\title{
What is the role of roles? Exploring the link between social roles and women's alcohol use in low- and middle-income countries
}

\author{
Ulrike Grittner $^{1,2}$, Zsofia Nemeth ${ }^{1,3}$, Sandra Kuntsche ${ }^{4}$, Beate Gaertner ${ }^{1,5}$, and Kim Bloomfield ${ }^{1,6}$ \\ ${ }^{1}$ Department for Biostatistics and Clinical Epidemiology, Charité - University Medical Centre Berlin, Berlin, Germany \\ ${ }^{2}$ Center for Stroke Research, Charité - University Medicine, Berlin, Germany \\ ${ }^{3}$ ELTE Faculty of Education and Psychology, Department of Clinical Psychology and Addiction, Budapest, Hungary \\ ${ }^{4}$ Addiction Switzerland, Research Institute, Lausanne, Switzerland \\ ${ }^{5}$ Robert Koch Institute, Department of Epidemiology and Health Monitoring, Berlin, Germany \\ ${ }^{6}$ Centre for Alcohol and Drug Research, Aarhus University, Copenhagen, Denmark
}

\begin{abstract}
Aims: This paper investigates how social roles are related to alcohol use among women in low- and middle-income countries.

Methods: Cross-sectional data were used from 25-49-years-old women in 11 low- and middle-income countries from the GenACIS project. Dependent variables were current drinking and risky drinking (10+gr/day). Information on partnership, parenthood and having paid labour were used as social role measures. Multiple and multilevel regression analyses were carried out to test whether holding several roles are related to current and risky drinking.
\end{abstract}

Results: Having paid work was associated with current and risky drinking across countries. Having a partner and having children were associated with a higher likelihood of abstention. With regard to country level characteristics per capita consumption was significantly related to both current drinking and risky drinking among women, while gross national income was significantly associated only with current drinking. Gender equality within the country did not have a significant association with women's drinking. Concerning differing role combinations, working single women without children were most likely to be risky drinkers, while women who were not working and had a partner and children were the least likely.

Conclusions: Paid labour was a substantial singular factor positively associated with women’s drinking. In addition, with the exception of Argentina and Kazakhstan, high per capita consumption on country level was associated with higher prevalence of risky drinking among women.

\section{Introduction}

Social epidemiological research on the association between women's socio-economic characteristics and their alcohol use has increased in recent years (Holmila \& Raitasalo, 2005; Kerr-Correa, Igami, Hiroce, \& Tucci, 2007; Rahav, Wilsnack, Bloomfield, Gmel, \& Kuntsche, 2006; Wilsnack et al., 2000), with a growing focus on how social roles relate to women's alcohol use (Christie-Mizell \& Peralta, 2009; Hajema \& Knibbe, 1998; Kuntsche et al., 2006; Kuntsche, Knibbe, \& Gmel, 2010a, b; Kuntsche, Knibbe, Kuntsche, \& Gmel, 2011;). Social roles are formed by enduring relations and obligations to other people such as partners, children, or work colleagues; they also define the social position that an individual holds within a society (McCall \& Simmons, 1996). Previous research has found evidence that, in addition to alcohol use, social roles are also related to various health behaviors such as physical activity and food choices (Bellows-Riecken \& Rhodes, 2008; Hartmann, Dohle, \& Siegrist, 2014).

Over the years, research has found evidence of an association between social roles and the social position of women to their alcohol use (Arber \& Khlat, 2002; Bernstein, 2001; Gmel, Bloomfield, Ahlstrom, Choquet, \& Lecomte, 2000; Kuntsche et al., 2011; Kuntsche et al., 2010 a, b; Lahelma, Arber, Kivela, \& Roos, 2002; Maclean, Glynn, \& Ansara, 2004; Neve, Lemmens, \& Drop, 1997; Peirce, Frone, Russell, \& Cooper, 1994). A recent study comparing alcohol use in ten high-income countries found general support for the "classic role theory" (Kuntsche et al., 2010b), which posits that a higher number of social roles is associated with a more structured life and thus with fewer opportunities to drink heavily (Hibbard \& Pope, 1991; Hong \& Seltzer, 1995).

Correspondence: Ulrike, Grittner, Department for Biostatistics and Clinical Epidemiology, Charité - University Medical Centre Berlin, Hindenburgdamm 30,12203 Berlin, Germany. Telephone: +49 30450562 162: E-mail: ulrike.grittner@charite.de

Competing interests: The authors declare that they have no conflict of interest with respect to their involvement in the publication between any commercial entities, participants personally and administrative units.

Financial support: See acknowledgements

Keywords: current drinking; risky drinking; paid labour; having a partner and children, alcohol, social roles, women 
Most of such research has focused almost exclusively on higher-income countries, and little is known about the relation of social roles and alcohol use among women in low- or middle-income countries (Wilsnack, Wilsnack, \& Obot, 2005). To focus attention to this area seems even more essential, as previous studies that have examined a wide range of countries suggest that the effect of women's social roles in lower- and middle-income countries could differ from patterns found in high-income countries. For instance, Grittner, Kuntsche, Gmel, and Bloomfield (2013) found that in lower-income countries women of high socioeconomic status engaged in risky single occasion drinking more often than did women of lower socio-economic status, an opposite pattern of that found for women in most of the studied high-income countries. Therefore, the aim of the present study is to examine the relationship of social roles to alcohol use among women in low- and middleincome countries.

Furthermore, the few existing studies of lower- and middleincome countries indicate that women's alcohol use has substantially distinct patterns (Room \& Selin, 2005). In some countries the prevalence of risky drinking is high, also among women (e.g., in Uganda; Tumwesigye \& Kasirye, 2005), while in others most women are lifetime abstainers and those who do drink alcohol drink moderate amounts (e.g., in India; Benegal, Nayak, Murthy, Chandra, \& Gururaj, 2005). However, these patterns are also subject to current dynamic changes (Martinez, Roislien, Naidoo, \& Clausen, 2011; Prasad, 2009).

Based on previous international studies (Kuntsche et al., 2011; Kuntsche et al., 2010b) one might assume that societal-level factors such as indicators of economic power of a country, drinking culture, and gender equality are also associated with women's drinking in low- and middleincome countries. Specifically, a key finding of one of these earlier studies among higher-income countries was that working mothers with a partner reported consuming more alcohol on drinking days than partnered housewives with children. However, gender income equity on the country level moderated this association: in countries with higher income equity, alcohol intake per drinking day was lower among working partnered mothers compared to partnered housewives with children; but in countries with lower income equity the opposite was present (Kuntsche et al., 2011).

Given this background of previous research, the present study set out to examine the relationship of three major social roles (parenthood, partnership, and employment) to alcohol use among women in 11 low- and middle-income countries. We also examined specific role combinations concerning their relationship to alcohol use, as no studies have investigated this in low- and middle-income countries. We additionally examined whether societal-level factors, such as the Gender Gap Index, per capita alcohol consumption, and gross national income [GNI], measured at the country level, were associated with alcohol use among women at the individual level (World Bank, 2008a, b).
Thus, this study investigates the following two research questions: First, how are the social roles of partnership, parenthood, and employment and their combinations related to alcohol use in low- and middle- income countries? Second, do additional country-level characteristics such as economic power, gender equity, or drinking culture explain variations in women's drinking between these countries?

\section{Method}

\section{Sample}

Data came from the project "Gender, Alcohol and Culture: An International Study" (GenACIS) that has been conducted in 39 countries (Bloomfield, Gmel, \& Wilsnack, 2006; Wilsnack, Wilsnack, Kristjanson, Vogeltanz-Holm, \& Gmel, 2009). Thirteen countries from the GenACIS data set were selected for this study on the basis of their classification as low- to middle-income countries for the year 2005 according to the World Bank. The year 2005 was chosen as it was nearest to the most survey years (World Bank, 2014, 2008a;b). Two countries, Mexico and Belize, did not include questions on parenthood in their surveys and thus were excluded from our final group of study countries. The remaining 11 low-, lower-middle-, and upper-middle-income countries (six American: Argentina, Brazil, Costa Rica, Nicaragua, Peru, and Uruguay; two African: Nigeria and Uganda; three Asian: India, Kazakhstan and Sri Lanka) represent different alcohol use cultures from Asia, Africa, and South and Central America.

The study data set comprised 4,985 women. The age range was restricted to 25-49 years based on the assumption that in this age range the probability of having at least one child under the age of 18 years is high. Moreover, we assume that most people in this age group have completed their educations and could have engaged in paid labor.

All surveys were conducted between 2002 and 2005 using face-to-face interviews. Response rates from surveys with random probability sampling ranged from 38-96\%, with a median of 68\% (see Wilsnack et al., 2009).

\section{Dependent variables}

Two measures assessed alcohol use. Because alcohol use is relatively rare among women in low- and middle-income countries, we first examined current alcohol use (yes vs. no) as one outcome variable (i.e., drinking alcohol at least once in the last 12 months). Secondly, we examined higher levels of alcohol intake (risky drinking), which was defined as drinking 10 grams or more of pure alcohol on average per day. Consumption above this threshold is reported to have detrimental effects to women's health (e.g., Australian Government \& National Health and Medical Research Council, 2009; Burger, Bronstrup, \& Pietrzik, 2004). In general, alcohol use has a dose-response relationship to alcohol-related health consequences (Corrao, Bagnardi, Zambon, \& Arico, 1999) that also seems to apply to women in non-western societies (e.g., Cherpitel, Ye, Bond, Borges, 
\& Monteiro, 2014; Qian et al., 2014). The measure of 10 grams of pure alcohol per day was derived from the calculation of annual volume based on beverage-specific questions pertaining to the past 12 months divided by 365 . Respondents were asked how many glasses or units (measured in the local metric) of the various beverage types of alcohol (beer, wine, spirits) they drank on a typical drinking day and how often they drank in the last 30 days (or in the last 12 months if less frequent than 30 days). These measures were then multiplied by beverage type and summed up to create a measure of total alcohol use in grams of pure alcohol.

\section{Independent variables}

Social roles were assessed by indicators on parenthood, partnership, and paid labor. Parenthood was defined as whether the respondent lived with any children younger than 18 years of age or not, including adopted children, stepchildren, partner's children, or grandchildren. The presence of underage children living in the household implied that women have child-raising responsibilities. Partnership was dichotomized into married / cohabiting versus other. From the variables of partnership and parenthood we constructed a new variable, family type, which had four role combinations: having a partner and any children, having a partner but no children, being single with any children, or being single with no children. Paid labor was also dichotomized into having any type of employment for payment (i.e., without regard to full-time or part-time, legal or illegal). For most countries this consisted of a single simple question: "What is your present daily occupation/employment status?” for which working for pay was one of eight answer options. Education was measured by asking respondents about their highest achieved education. This was coded according to years of schooling: low (not more than 10 years of education); middle (more than 10 years but less than 13 years); or high (13 or more years).

\section{Societal-level variables}

We used GNI per capita in United States dollars (USD) that was the closest to the survey year from the World Bank as measure of economic power of a country (World Bank, 2008a, b). Data from the World Health Organisation (WHO) on recorded and unrecorded per capita pure alcohol consumption for individuals 15 years and older in liters from 2005 were also included as a rough measure of the drinking culture of a country (WHO, 2011).

Gender equality was measured by the 2006 Gender Gap Index, an indicator developed by the World Economic Forum that reflects gender-based disparities in the field of economic participation, political empowerment, educational attainment, and health (Hausmann, Tyson, \& Zahidi, 2011). Its scores are on a 0 to 1 scale $(0=$ total inequality, 1 = total equality).

\section{Statistical analysis}

Country-specific odds ratios with current drinking and risky drinking as dependent variables were calculated by using multiple logistic regression models. Family type (the combination of partnership and parenthood) and paid labor were the independent variables representing social role combinations and all analyses were adjusted for age and educational level.

The prevalence of risky drinking was too low to conduct multiple regression analyses in Brazil, India, Peru, and Sri Lanka, and thus these countries were omitted for the country-specific analyses of risky drinking. Finally, data from all countries were combined and multilevel logistic regressions (random intercept models) were conducted with current drinking and risky drinking as dependent variables and age, education, family type, paid labor, GNI, gender gap index, and per capita consumption as independent variables. Additionally we tested how societal-level characteristics moderate the relation between social roles and alcohol consumption by including cross-level interaction terms for GNI/per capita consumption and paid labor/family type. Also the data from Brazil, India, Peru, and Sri Lanka were used in the multilevel logistic regression models.

For the statistical analyses we used SPSS (IBM Corp, released 2011) and SAS software version 9.2 of the SAS System for Windows. Significance was tested at the $\alpha$ level of 0.05. No adjustment for multiple testing was applied.

\section{Results}

Table 1 provides an overview of the study variables by country. In India and Sri Lanka few women were current alcohol drinkers (<10\%). In the South American countries Argentina, Peru, and Uruguay, and in the Asian country Kazakhstan, the majority of women were current drinkers (61-76\%). In general it appears that in countries where women's alcohol use was more common, risky drinking among women was relatively low (1-7\%). However, in Nigeria and Uganda, where the prevalence of women with current alcohol use was rather low (22-41\%), the percentage of women engaging in risky drinking was relatively high compared to other countries (around 12\%), reflecting that among those women who drank alcohol in these countries, between $30-50 \%$ were risky drinkers. Overall, however, there were relatively few women currently drinking (34\%) and a low prevalence of women engaging in risky drinking (5\%).

The frequencies of the various family types across the whole sample were as follows: $68 \%$ of the women had a partnership and any children (range: 54-86\%); $8 \%$ had a partnership but no children (range: 1-15\%); 15\% were single with any children (range: 5-25\%); 10\% were single with no children (range: 6-18\%) (range:) (data not shown in table). The proportion of women in paid labor varied: from about $20 \%$ in Sri Lanka to almost $60 \%$ in Uruguay (Table 1). 
Table 1

Country characteristics: age, education, partnership, parenthood, paid work, current drinking, risky drinking, and gross national income, per capita consumption and gender gap index by country

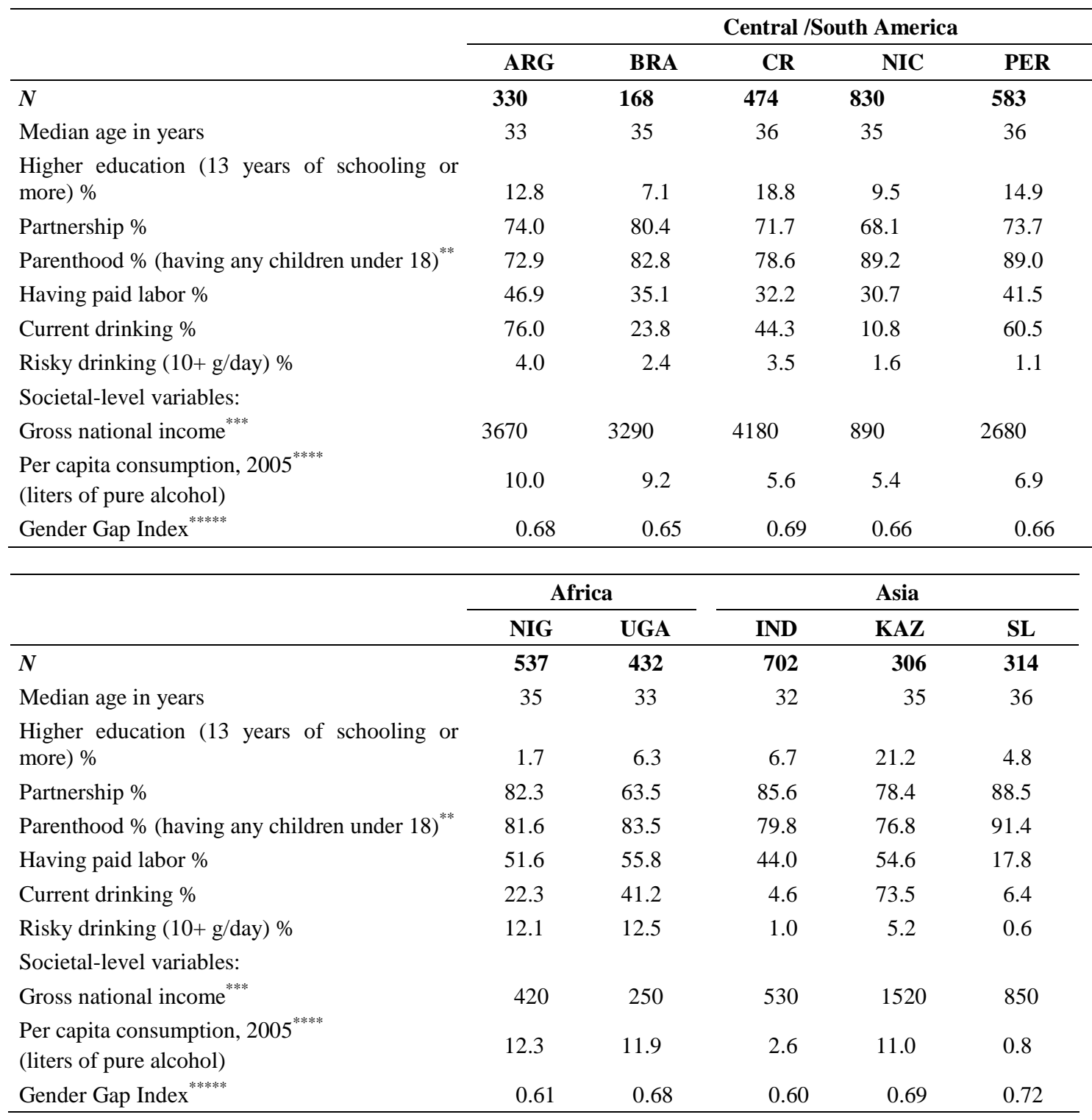

${ }^{* * *}$ In Nicaragua only data about children without age limit (thus not only below 18) were available.

**** World Bank data from the year of the survey completed in United States dollars.

${ }^{* * * * *}$ World Health Organisation (2011), Recorded and unrecorded adult consumption in litres, 2005

Note: ARG=Argentina, BRA=Brazil, CR=Costa Rica, IND=India, KAZ=Kazakhstan, NIC=Nicaragua, NIG=Nigeria, PER=Peru, $\mathrm{SL}=$ Sri Lanka, UGA=Uganda, URU=Uruguay

${ }^{* * * * * *}$ Hausmann et al., 2011

Among the societal-level variables, annual GNI and per capita pure alcohol consumption varied substantially between the countries. Costa Rica had the highest GNI, at more than 4000 USD, while Uganda had the lowest, at 250 USD. Regarding per capita consumption (in year 2005) Nigeria had the highest estimate at over 12 liters of pure alcohol, and Sri Lanka the lowest with less than one liter of pure alcohol. The Gender Gap Index displayed little variation.
For testing the first research question regarding the association of different roles to alcohol use, odds ratios assessing the relationship of paid labor and the various combinations of family types to the drinking outcome variables are displayed in Table 2. The top half of the table displays the odds ratios for current drinking. Having paid labor was consistently positively related to current drinking; however, it was statistically significant in only five of the 11 countries: Brazil, Argentina, Nigeria, 
Kazakhstan, and Sri Lanka. Family types were not significantly associated to current drinking in most of the countries, but in general those having a partnership and any children were less often current drinkers than the three other family types. Only in Argentina, Nigeria, and India were singles with no children significantly more likely to be current drinkers than those with a partnership and any children.
The bottom half of Table 2 displays results for risky drinking as the outcome. In Argentina and Nigeria, paid labor was significantly related to risky drinking. Family types showed no consistent association with risky drinking across countries, but a general (non-significant) trend was that those with a partnership and any children were less often risky drinkers.

Table 2

Country-specific multiple logistic regressions for social roles and drinking variables

\begin{tabular}{|c|c|c|c|c|c|c|}
\hline \multirow{3}{*}{ Countries } & & \multicolumn{5}{|c|}{ Central/South America } \\
\hline & & ARG & BRA & CR & NIC & PER \\
\hline & $N$ & 326 & 168 & 474 & 830 & 583 \\
\hline \multicolumn{7}{|c|}{ Current drinking } \\
\hline $\begin{array}{l}\text { (ref: no paid } \\
\text { labor) }\end{array}$ & Paid labor & $\begin{array}{c}1.95 \\
(1.05-3.62)\end{array}$ & $\begin{array}{c}2.83 \\
(1.15-6.94)\end{array}$ & $\begin{array}{c}1.38 \\
(0.82-2.33)\end{array}$ & $\begin{array}{c}1.27 \\
(0.78-2.05)\end{array}$ & $\begin{array}{c}1.12 \\
(0.78-1.62)\end{array}$ \\
\hline \multirow{3}{*}{$\begin{array}{l}\text { Family types } \\
\text { (ref: partner } \\
\text { and any } \\
\text { children }\end{array}$} & $\begin{array}{l}\text { Partner and no } \\
\text { children }\end{array}$ & $\begin{array}{c}0.88 \\
(0.40-1.95)\end{array}$ & $\begin{array}{c}6.42 \\
(1.59-25.92)\end{array}$ & $\begin{array}{c}1.80 \\
(0.78-4.19)\end{array}$ & $\begin{array}{c}1.46 \\
(0.48-4.45)\end{array}$ & $\begin{array}{c}2.25 \\
(0.37-13.63)\end{array}$ \\
\hline & $\begin{array}{l}\text { Single and any } \\
\text { children }\end{array}$ & $\begin{array}{c}1.07 \\
(0.46-2.44)\end{array}$ & $\begin{array}{c}0.83 \\
(0.17-4.00)\end{array}$ & $\begin{array}{c}1.85 \\
(0.97-3.53)\end{array}$ & $\begin{array}{c}1.43 \\
(0.85-2.41)\end{array}$ & $\begin{array}{c}1.04 \\
(0.65-1.69)\end{array}$ \\
\hline & $\begin{array}{l}\text { Single and no } \\
\text { children }\end{array}$ & $\begin{array}{c}3.84 \\
(1.13-12.98)\end{array}$ & $\begin{array}{c}2.31 \\
(0.56-9.56)\end{array}$ & $\begin{array}{c}0.98 \\
(0.48-2.01)\end{array}$ & $\begin{array}{c}1.69 \\
(0.80-3.54)\end{array}$ & $\begin{array}{c}0.90 \\
(0.48-1.63)\end{array}$ \\
\hline $\begin{array}{l}\text { Risky drinking } \\
\text { (ref: no paid } \\
\text { labor) }\end{array}$ & Paid labor & $\begin{array}{c}5.51 \\
(1.28-23.83)\end{array}$ & $\begin{array}{c}0.16 \\
(0.01-2.58)\end{array}$ & $\begin{array}{c}1.22 \\
(0.33-4.51)\end{array}$ & $\begin{array}{c}1.16 \\
(0.35-3.82)\end{array}$ & $\begin{array}{c}5.91 \\
(0.69-50.5)\end{array}$ \\
\hline \multirow{3}{*}{$\begin{array}{l}\text { Family types } \\
\text { (ref: partner } \\
\text { and any } \\
\text { children }\end{array}$} & $\begin{array}{l}\text { Partner and no } \\
\text { children }\end{array}$ & $\begin{array}{c}2.10 \\
(0.46-9.63)\end{array}$ & -- & $\begin{array}{c}3.84 \\
(0.67-22.11)\end{array}$ & $\begin{array}{c}2.77 \\
(0.31-24.86)\end{array}$ & -- \\
\hline & $\begin{array}{l}\text { Single and any } \\
\text { children }\end{array}$ & $\begin{array}{c}0.68 \\
(0.11-4.28)\end{array}$ & -- & $\begin{array}{c}3.66 \\
(0.77-17.36)\end{array}$ & $\begin{array}{c}2.53 \\
(0.75-8.51)\end{array}$ & $\begin{array}{c}0.06 \\
(0-142.75)\end{array}$ \\
\hline & $\begin{array}{l}\text { Single and no } \\
\text { children }\end{array}$ & $\begin{array}{c}0.20 \\
(0.01-8.98) \\
\end{array}$ & -- & $\begin{array}{c}2.65 \\
(0.48-14.64) \\
\end{array}$ & $\begin{array}{c}0.99 \\
(0.11-8.83) \\
\end{array}$ & $\begin{array}{c}2.29 \\
(0.32-16.46) \\
\end{array}$ \\
\hline \multirow{3}{*}{ Countries } & & \multicolumn{2}{|c|}{ Africa } & \multicolumn{3}{|c|}{ Asia } \\
\hline & & NIG & UGA & IND & KAZ & SL \\
\hline & $N$ & 537 & 432 & 702 & 306 & 314 \\
\hline \multicolumn{7}{|c|}{ Current drinking } \\
\hline $\begin{array}{l}\text { (ref: no paid } \\
\text { labor) }\end{array}$ & Paid labor & $\begin{array}{c}1.75 \\
(1.12-2.74)\end{array}$ & $\begin{array}{c}1.02 \\
(0.68-1.52)\end{array}$ & $\begin{array}{c}1.56 \\
(0.72-3.39)\end{array}$ & $\begin{array}{c}3.24 \\
(1.77-5.93)\end{array}$ & $\begin{array}{c}3.89 \\
(1.36-11.08)\end{array}$ \\
\hline \multirow{3}{*}{$\begin{array}{l}\text { Family types } \\
\text { (ref: partner } \\
\text { and any } \\
\text { children }\end{array}$} & $\begin{array}{l}\text { Partner and no } \\
\text { children }\end{array}$ & $\begin{array}{c}1.20 \\
(0.57-2.55)\end{array}$ & $\begin{array}{c}0.40 \\
(0.14-1.13)\end{array}$ & $\begin{array}{c}2.29 \\
(0.82-6.43)\end{array}$ & $\begin{array}{c}0.58 \\
(0.26-1.30)\end{array}$ & $\begin{array}{c}2.52 \\
(0.27-23.68)\end{array}$ \\
\hline & $\begin{array}{l}\text { Single and any } \\
\text { children }\end{array}$ & $\begin{array}{c}2.00 \\
(1.02-3.91)\end{array}$ & $\begin{array}{c}0.62 \\
(0.38-1.01)\end{array}$ & $\begin{array}{c}1.35 \\
(0.29-6.28)\end{array}$ & $\begin{array}{c}2.18 \\
(0.71-6.67)\end{array}$ & -- \\
\hline & $\begin{array}{l}\text { Single and no } \\
\text { children }\end{array}$ & $\begin{array}{c}3.14 \\
(1.59-6.19)\end{array}$ & $\begin{array}{c}1.11 \\
(0.59-2.12)\end{array}$ & $\begin{array}{c}3.57 \\
(1.39-9.19)\end{array}$ & $\begin{array}{c}0.76 \\
(0.31-1.87)\end{array}$ & $\begin{array}{c}1.11 \\
(0.22-5.67)\end{array}$ \\
\hline $\begin{array}{l}\text { Risky drinking } \\
\text { (ref: no paid } \\
\text { labor) }\end{array}$ & Paid labor & $\begin{array}{c}2.35 \\
(1.31-4.22)\end{array}$ & $\begin{array}{c}1.05 \\
(0.57-1.94)\end{array}$ & $\begin{array}{c}0.75 \\
(0.15-3.71)\end{array}$ & $\begin{array}{c}1.07 \\
(0.36-3.16)\end{array}$ & $\begin{array}{c}6.49 \\
(0.33-128.74)\end{array}$ \\
\hline \multirow{3}{*}{$\begin{array}{l}\text { Family types } \\
\text { (ref: partner } \\
\text { and any } \\
\text { children }\end{array}$} & $\begin{array}{l}\text { Partner and no } \\
\text { children }\end{array}$ & $\begin{array}{c}1.05 \\
(0.39-2.85)\end{array}$ & $\begin{array}{c}0.60 \\
(0.15-2.34)\end{array}$ & $\begin{array}{c}1.84 \\
(0.26-12.93)\end{array}$ & $\begin{array}{c}1.49 \\
(0.27-8.12)\end{array}$ & -- \\
\hline & $\begin{array}{l}\text { Single and any } \\
\text { children }\end{array}$ & $\begin{array}{c}1.06 \\
(0.43-2.61)\end{array}$ & $\begin{array}{c}0.48 \\
(0.20-1.11)\end{array}$ & -- & $\begin{array}{c}2.34 \\
(0.64-8.60)\end{array}$ & -- \\
\hline & $\begin{array}{l}\text { Single and no } \\
\text { children }\end{array}$ & $\begin{array}{c}2.03 \\
(0.89-4.64)\end{array}$ & $\begin{array}{c}1.05 \\
(0.44-2.51)\end{array}$ & $\begin{array}{c}4.11 \\
(0.51-32.81)\end{array}$ & $\begin{array}{c}1.65 \\
(0.33-8.23)\end{array}$ & $\begin{array}{c}8.22 \\
(0.45-151.92) \\
\end{array}$ \\
\hline
\end{tabular}

Odds ratios and confidence intervals 95\% for the association between current drinking and risky drinking and social roles by country; all adjusted for age and educational level

Note: ARG=Argentina, BRA=Brazil, CR=Costa Rica, IND=India, KAZ=Kazakhstan, NIC=Nicaragua, NIG=Nigeria, PER= Peru, SL=Sri Lanka, UGA=Uganda, URU=Uruguay

bold: $p<.05$ 
In order to gain more power for testing the first research question and additionally to include societal-level indicators (our second research question), multilevel logistic regression was conducted across all countries (Table 3). Paid labor was significantly and positively related to both outcome measures of current and risky drinking, as was the family type of being single with no children. GNI proved to be significant with regard to current drinking. Per capita pure alcohol consumption was significantly related to both current and risky drinking. Gender equality was tested, but was not significantly associated with either of the drinking outcomes and therefore was not included in the final models. The interaction between per capita consumption and family type was significant indicating that especially in countries with general higher consumption levels the differences in alcohol consumption with regard to family types are even more pronounced than in countries with lower levels of alcohol consumption.

Table 3

Odds ratios and 95\% confidence intervals of the association between social roles, age, education, gross national income, per capita pure alcohol consumption (independent) and current drinking / risky drinking (dependent) from a multilevel logistic model (random intercept models) (all countries included)

\begin{tabular}{|c|c|c|}
\hline & $\begin{array}{l}\text { Current drinking } \\
\qquad N=4985\end{array}$ & $\begin{array}{c}\text { Risky drinking } \\
\quad N=4984\end{array}$ \\
\hline Fixed effects & $O R(95 \% \mathrm{CI})$ & OR $(95 \% \mathrm{CI})$ \\
\hline Age in decades (centered) & $0.94(0.85-1.05)$ & $1.10(0.89-1.35)$ \\
\hline \multicolumn{3}{|l|}{ Education (reference: high) } \\
\hline Low & $0.46(0.35-0.59)$ & $0.60(0.37-0.97)$ \\
\hline Middle & $0.67(0.52-0.85)$ & $0.84(0.53-1.34)$ \\
\hline Paid labor (reference: no paid labor) & $1.43(1.23-1.67)$ & $1.60(1.18-2.17)$ \\
\hline \multicolumn{3}{|l|}{ Family type (reference: having a partner and any children) } \\
\hline Partner and no children & $1.15(0.84-1.56)$ & $2.55(1.41-4.63)$ \\
\hline Single and any children & $1.18(0.95-1.48)$ & $1.43(0.80-2.53)$ \\
\hline Single and no children & $1.53(1.19-1.97)$ & $2.81(1.67-4.74)$ \\
\hline Gross national income & $1.65(1.27-2.14)$ & $0.94(0.78-1.15)$ \\
\hline Per capita pure alcohol consumption (centered) (PCC ${ }^{\mathrm{a}}$ ) & $1.29(1.16-1.45)$ & $1.37(1.23-1.53)$ \\
\hline \multicolumn{3}{|l|}{ Cross-level interaction } \\
\hline \multicolumn{3}{|c|}{$\begin{array}{l}\text { PCC * family type (reference: having a partner and any children in a } \\
\text { country with around } 7 \text { litres of PCC) }\end{array}$} \\
\hline Partner and no children*PCC & $1.15(1.00-1.31)$ & $1.15(0.99-1.33)$ \\
\hline Single and any children*PCC & $1.27(1.12-1.45)$ & $1.22(1.05-1.42)$ \\
\hline Single and no children*PCC & $1.27(1.11-1.44)$ & $1.19(1.04-1.36)$ \\
\hline Random effects & beta $(S E)$ & beta $(S E)$ \\
\hline variance between countries & $0.42(0.19)$ & $0.16(0.11)$ \\
\hline
\end{tabular}

bold: $p<.05$
${ }^{\text {a }}$ PCC: per capita consumption

bold: $p<.05$
${ }^{\mathrm{a}}$ PCC: per capita consumption
To aid in visualizing the relationship between paid labor, family types and drinking indicators eight groups were created (four different family types stratified by having paid labor or not) and plotted against current drinking and risky drinking for all countries combined. Figure 1 shows that, firstly, women in paid labor were more often current drinkers. In particular, working singles without children were most often current drinkers than other women. Amongst all working women, mothers living together with a partner were the least likely to drink currently. Among non-employed women a lower proportion of current irrespective of whether they had any children or not. With regard to risky drinking, Figure 1 shows a similar pattern: working singles without children were most likely to be risky drinkers while non-working women with a partner and any children were the least likely. The figure clearly displays the effect of the role of paid labor on both drinking indicators. It also shows that those with a partner and children but without work had the lowest proportion of current or risky drinking. drinking was found for those who had a partner, 
Figure 1

The relationship between paid labor, family types, and drinking indicators

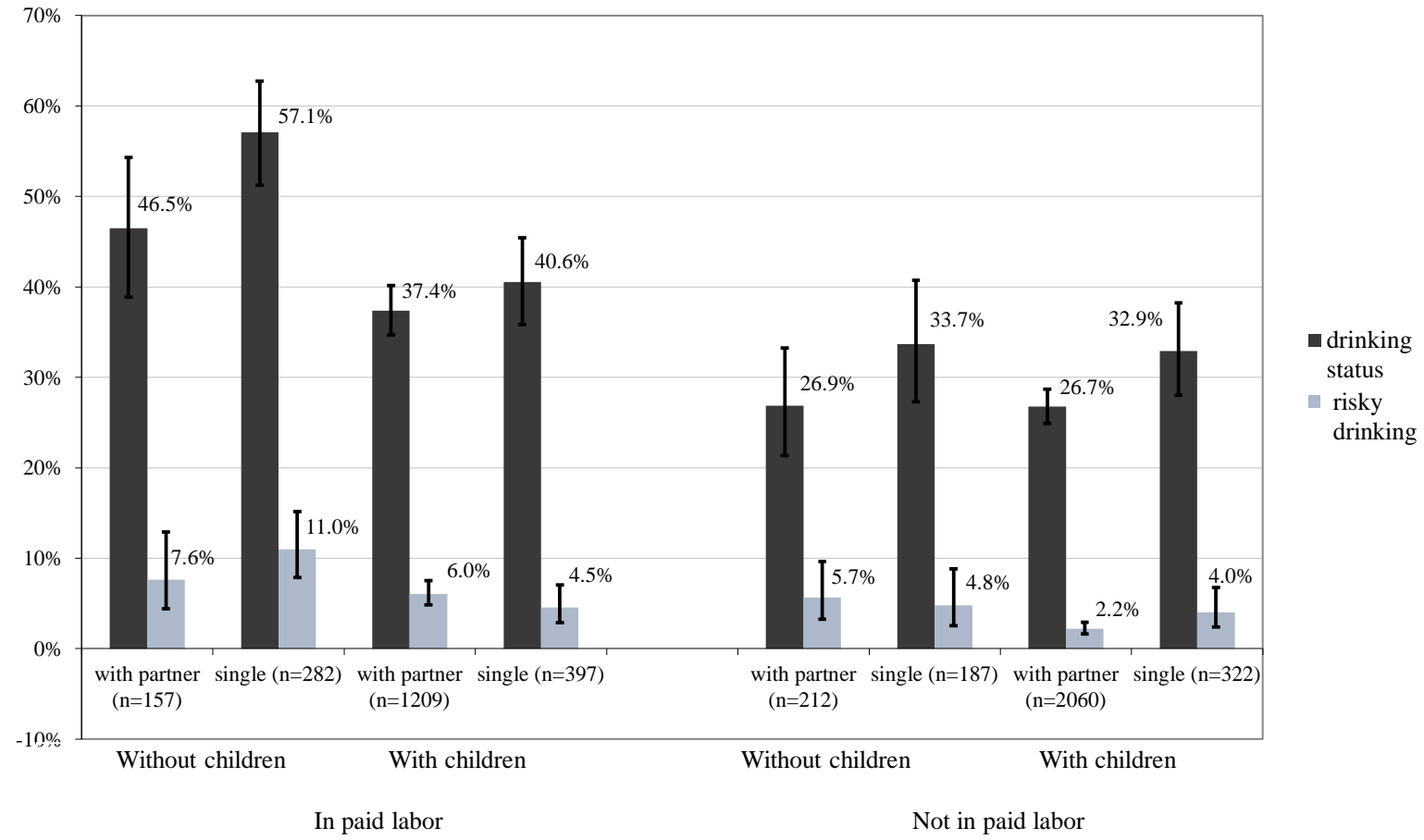

\section{Discussion}

The aim of the present study was to investigate how social roles are related to current drinking and risky drinking among women in low- and middle-income countries. In line with earlier studies on low-income countries (Room \& Selin, 2005), our study showed that in almost half of the study countries (Brazil, India, Sri Lanka, Nicaragua, and Nigeria), abstention was the norm. This may be attributed to religion and cultural traditions (Bernards, Graham, Kuendig, Hettige, \& Obot, 2009).

With regard to our first research question on how these social roles are related to alcohol use in women, we found that the relationship to current and risky drinking varied depending on specific roles or specific role combinations.

Thus, the findings of the present study will first be summarized for each of the three analyzed roles (paid labor, parenthood, partnership). Our study results reveal that paid labor was related to current and risky drinking. With regard to the other two roles, parenthood and partnership, we found that women with a partner and children were least likely to be current drinkers or risky drinkers, whereas single women without children were most likely to be current and risky drinkers.

With regard to the positive association found between paid labor and alcohol use, earlier studies have been inconsistent in this respect (Ahlström, Bloomfield, \& Knibbe, 2001;
Gmel et al., 2000; Kerr-Correa et al., 2007). It has been shown that the relationship of risky drinking and paid labor depends on the social-security system of a country and on policies making work desirable for women, in particular for mothers (Ahlström et al., 2001; Gmel et al., 2000; Kuntsche et al., 2011). For instance, Gmel et al. (2000) found that employment was positively related to risky drinking in Switzerland but was negatively associated in Finland. In a study by Ahlström et al. (2001), unemployment was related to women's drinking. Our results on low- and middle-income countries show that working women are more likely to drink $10 \mathrm{~g}$ of pure alcohol or more per day than women without paid labor. We can only speculate as to the reasons for this. It could be due to leisure, to cope with stress at work, to adopt a more masculine behavior, to having more financial independence, or to having opportunities to drink outside their homes. More longitudinal research is needed to understand what happens after becoming employed or after losing a job.

Based on the results of the present study, parenthood was associated with abstention or moderate drinking in many countries. This is consistent with earlier studies that found that parenthood structures the lives of parents, especially mothers, and decreases the opportunities to drink (Ahlström et al., 2001; Kerr-Correa et al., 2007; Little, Handley, Leuthe, \& Chassin, 2009).

In contrast to past findings regarding role theory, where emphasis is placed on the accumulation of roles as a 
protective factor, our study indicates that it is the kind of role, rather than the number of social roles, that is decisive. While women with the two roles of having a partner and any children showed the lowest proportion of risky drinking, women with other combinations of two roles (e.g., having a paid job and a partner, having a paid job and any children) indicated a higher proportion of risky drinking. Similarly, regarding singular roles, women with the one role of having any children had a low proportion of risky drinking, while women with only a paid job or with only a partner were found to have a higher proportion of risky drinking.

This study comprises an analysis of women's drinking and the relationship between social roles and alcohol consumption in 11 low- and middle-income countries. These countries also represent diverse drinking cultures. In comparison to high-income countries our study countries had relatively low rates of current drinking, yet Argentina, Kazakhstan, and Peru had relatively high rates (more than $50 \%$ ) compared to India and Sri Lanka, where $95 \%$ of all women were abstainers and where women's drinking is highly proscribed (Benegal et al., 2005; Hettige \& Paranagama, 2005). Despite these relatively low rates of current drinking, the proportion of risky drinking women Nigeria and Uganda was comparatively high (7\% or more). However, the most consistent finding - that having paid labor was associated with a higher probability of current drinking - was present in all study countries (Table 2, odds ratio $>1$ ). Furthermore, it is interesting that in nine out of the 11 countries, paid labor was also associated with risky drinking (except for Brazil and India). Similarly, the consistent finding that single women without children were more often current drinkers (in eight out of 11 countries) and more often risky drinkers (in eight out of 10 countries) than partnered women with children is a rather astonishing finding. One explanation could be that single women without children might have more free time to socialize with friends or might be searching for a partner and therefore visit places where men are present, where consumption of alcohol is more common, and where women who drink are more accepted.

With regard to the second research question as to whether variation in drinking can be explained by country-specific characteristics, our present study used the Gender Gap Index to assess gender inequity. An earlier study of Kuntsche et al. (2011) found a positive association between higher gender income equality and the classic role theory; that is, in countries with gender income equality, women with more roles reported less risky alcohol use. However, the Gender Gap Index did not prove to be significant in our study. This could be due to either the low variation in the index across the study countries (see Table 1 ) or that the indicator is not sensitive enough: some research assumes that in countries with low gender equity women's alcohol use takes on symbolic meanings such that working women express their power, masculinity, or modernity through drinking in a male-dominated surrounding (Holmila \& Raitasalo, 2005; Wilsnack et al., 2000) and thus would tend to drink in a risky fashion.
Regarding other societal-level variables, GNI was significantly associated with current drinking, but not with risky drinking. This may reflect the possibility that the study countries with a higher GNI share living conditions and cultures similar to those in higher-income countries where a higher prevalence of current drinking among women and higher percentages of employed women are the norm. In contrast, an earlier study found no association between GNI and drinking within higher income countries (Kuntsche et al., 2011). These conflicting results may indicate that GNI is a more sensitive correlate of women's drinking status in low- and middle-income countries.

We found a positive association between per capita consumption of pure alcohol and the probability of women being current or risky drinkers (Table 3). Therefore, women in countries with higher per capita alcohol consumptions have a greater chance of being current or risky drinkers. Among our study countries, Argentina and Kazakhstan had the fourth and third highest per capita consumption and the two highest proportions of current drinkers (Table 1). In contrast, Nigeria, with the highest per capita consumption among our study countries, belongs to the countries with the lowest proportions of current drinkers among women. This is in line with previous results that per capita consumption levels are mainly driven by the higher levels of consumption of men and that drinking habits can be very different for men and women within a country. Additionally we found a moderation effect of per capita consumption on the relation between family type and alcohol consumption: in countries with higher levels of consumption, the differences in women's drinking with regard to family types were even more pronounced than in countries with lower levels.

\section{Limitations}

The present study has some limitations. One of these is the small number within certain subgroups such as working women, risky drinkers, or certain combinations of social roles. Only in four countries out of 11 were the majority of women (> 50\%) current drinkers, and in three countries not even one woman out of nine could be considered a current drinker. Thus, the present study was based on a small sample of current drinkers. Furthermore, in the interest of comparability of 11 countries, the analysis was restricted to rather crude measures of social roles. Thus, it was not possible to distinguish among various types of work, for example, or more specific family constellations. Another limitation concerns the cross-sectional design of the study, which did not allow establishing causal interpretation of the relationships. Furthermore, our study could not include the use of other variables on gender-based disparities at the country level.

\section{Conclusions}

In summary, this study provides evidence for the notable role that paid labor has in women's drinking in low- and middle-income countries. Having paid labor might contribute to taking up an emancipated lifestyle, nontraditional roles, and behavior patterns that contradict the norm of abstinence often expected of women in these 
countries. Nevertheless, concerning our limited knowledge about these countries it would be important to implement regular health monitoring systems to gain detailed insight in drinking motives and situations in those countries. As some of these countries face economic transitions this could have implications on the economic power and the employment status of women living there. How these transitions affect their alcohol consumption requires further research. Furthermore, the use of other variables on gender-based disparities of a country would be interesting in future research.

\section{Acknowledgements}

The data used in this paper are from the project Gender, Alcohol, and Culture: An International Study (GENACIS). GENACIS is a collaborative international project affiliated with the Kettil Bruun Society for Social and Epidemiological Research on Alcohol and coordinated by GENACIS partners from the University of North Dakota, Aarhus University, the Alcohol Research Group/Public Health Institute, the Centre for Addiction and Mental Health, the University of Melbourne, and the Swiss Institute for the Prevention of Alcohol and Drug Problems. Support for aspects of the project comes from the World Health Organization, the Quality of Life and Management of Living Resources Programme of the European Commission (Concerted Action QLG4-CT-2001-0196), the U.S. National Institute on Alcohol Abuse and Alcoholism/National Institutes of Health (Grants R21 AA012941 and R01 AA015775), the Pan American Health Organization, and Swiss national funds. Support for individual country surveys was provided by government agencies and other national sources. The study leaders and funding sources for data sets used in this report are: Argentina: Myriam Munné, M.S., World Health Organization; Brazil: Florence Kerr-Corréa, M.D., Ph.D., Foundation for the Support of Sao Paulo State Research (Fundação de Amparo a Pesquisa do Estado de São Paulo, FAPESP) (Grant 01/03150-6); Costa Rica: Julio Bejarano, M.Sc., World Health Organization; India: Vivek Benegal, M.D., World Health Organization; Kazakhstan: Bedel Sarbayev, Ph.D., World Health Organization; Nicaragua: José Trinidad Caldera Aburto, M.D., Ph.D., Pan American Health Organization; Nigeria: Akanidomo Ibanga, M.Sc., World Health Organization; Peru: Marina Piazza, World Health Organization; Sri Lanka: Siri Hettige, Ph.D., World Health Organization; Uganda: M. Nazarius Tumwesigye, Ph.D., World Health Organization; USA: Thomas Greenfield, Ph.D., National Institute on Alcohol Abuse and Alcoholism/ National Institutes of Health (Grant P50 AA05595); Uruguay: Raquel Magri, M.D., World Health Organization. A post-doc scholarship of Z. Nemeth, Ph.D. was granted by DAAD (German Academic Exchange Service).

\section{References}

Ahlström, S., Bloomfield, K., \& Knibbe, R. (2001). Gender differences in drinking patterns in nine European countries: Descriptive findings. Journal of Substance Abuse Treatment, 22(1), 69-85. doi:10.1080/ 08897070109511446

Arber, S., \& Khlat, M. (2002). Introduction to 'social and economic patterning of women's health in a changing world. Social Science and Medicine, 54(5), 643-647.

Australian Government \& National Health and Medical Research Council. (2009). Australian guidelines to reduce health risks from drinking alcohol. Commonwealth of Australia: Author.

Bellows-Riecken, K. H., \& Rhodes, R. E. (2008). A birth of inactivity? A review of physical activity and parenthood. Preventive Medicine, 46(2), 99-110. doi:10.1016/j.ypmed.2007.08.003

Benegal, V., Nayak, M., Murthy, P., Chandra, P., \& Gururaj, G. (2005). Women and alcohol in India. In I. S. Obot \& R. Room (Eds.), Alcohol, gender and drinking problems. Perspectives from low and middle income countries (pp. 89-123). Geneva, Switzerland: World Health Organization.

Bernards, S., Graham, K., Kuendig, H., Hettige, S., \& Obot, I. (2009). 'I have no interest in drinking': A cross-national comparison of reasons why men and women abstain from alcohol use. Addiction, 104(10), 1658-1668. doi:10.1111/j.1360-0443.2009.02667.x

Bernstein, A. B. (2001). Motherhood, health status, and health care. Women's Health Issues, 11(3), 173-184.

Bloomfield, K., Gmel, G., \& Wilsnack, S. (2006). Gender, culture and alcohol problems: A multi-national study. Alcohol and Alcoholism, 41(Suppl. 1), i3-i7. doi:10.1093/alcalc/agl070

Burger, M., Bronstrup, A., \& Pietrzik, K. (2004). Derivation of tolerable upper alcohol intake levels in Germany: A systematic review of risks and benefits of moderate alcohol consumption. Preventive Medicine, 39(1), 111-127. doi:10.1016/j.ypmed.2003.11.011

Cherpitel, C. J., Ye, Y., Bond, J., Borges, G., \& Monteiro, M. (2014). Relative risk of injury from acute alcohol consumption: Modeling the dose-response relationship in emergency department data from 18 countries. Addiction, 110(2), 279-288. doi:10.1111/add.12755

Christie-Mizell, C. A., \& Peralta, R. L. (2009). The gender gap in alcohol consumption during late adolescence and young adulthood: Gendered attitudes and adult roles. Journal of Health and Social Behavior, 50(4), 410-426.

Corrao, G., Bagnardi, V., Zambon, A., \& Arico, S. (1999). Exploring the dose-response relationship between alcohol consumption and the risk of several alcoholrelated conditions: A meta-analysis. Addiction, 94(10), 1551-1573.

Gmel, G., Bloomfield, K., Ahlstrom, S., Choquet, M., \& Lecomte, T. (2000). Women's roles and women's drinking: A comparative study in four European countries. Journal of Substance Abuse Treatment, 21(4), 249-264. doi:10.1080/08897070009511437

Grittner, U., Kuntsche, S., Gmel, G., \& Bloomfield, K. (2013). Alcohol consumption and social inequality at the individual and country levels. Results from an international study. European Journal of Public Health, 23(2), 332-339. doi:10.1093/eurpub/cks044 
Hajema, K. J., \& Knibbe, R. A. (1998). Changes in social roles as predictors of changes in drinking behaviour. Addiction, 93(11), 1717-1727.

Hartmann, C., Dohle, S., \& Siegrist, M. (2014). Time for change? Food choices in the transition to cohabitation and parenthood. Public Health Nutrition, 17(12), 2730-2739. doi:10.1017/S1368980013003297

Hausmann R., Tyson L.D., \& Zahidi S. (2011). The global gender gap report 2011. Geneva, Switzerland: The World Economic Forum.

Hettige, S., \& Paranagama, D. (2005). Gender and alcohol in Sri Lanka. In I. S. Obot \& R. Room (Eds.), Alcohol, gender and drinking problems. Perspectives from low and middle income countries (pp.167-188). Geneva, Switzerland: World Health Organization.

Hibbard, J. H., \& Pope, C. R. (1991). Effect of domestic and occupational roles on morbidity and mortality. Social Science and Medicine, 32(7), 805-811.

Holmila, M., \& Raitasalo, K. (2005). Gender differences in drinking: Why do they still exist? Addiction, 100(12), 1763-1769. doi:10.1111/j.1360-0443.2005.01249.x

Hong, J., \& Seltzer, M. M. (1995). The psychological consequences of multiple roles: The nonnormative case. Journal of Health and Social Behavior, 36(4), 386-398.

Kerr-Correa, F., Igami, T. Z., Hiroce, V., \& Tucci, A. M. (2007). Patterns of alcohol use between genders: A cross-cultural evaluation. Journal of Affective Disorders, 102(1-3), 265-275. doi:10.1016/j.jad.2006. 09.031

Kuntsche, S., Gmel, G., Knibbe, R. A., Kuendig, H., Bloomfield, K., Kramer, S., \& Grittner, U. (2006). Gender and cultural differences in the association between family roles, social stratification, and alcohol use: A European cross-cultural analysis. Alcohol and Alcoholism, 41(Suppl. 1), i37-i46. doi:10.1093/alcalc/ agl074

Kuntsche, S., Knibbe, R. A., \& Gmel, G. (2010a). A step beyond-The relevance of depressed mood and mastery in the interplay between the number of social roles and alcohol use. Addictive Behaviors, 35(11), 1013-1020. doi:10.1016/j.addbeh.2010.06.020

Kuntsche, S., Knibbe, R. A., \& Gmel, G. (2010b). Social roles and alcohol consumption: A study of 10 industrialised countries. Social Science and Medicine, 68, 1263-1270.

Kuntsche, S., Knibbe, R. A., Kuntsche, E., \& Gmel, G. (2011). Housewife or working mum-Each to her own? The relevance of societal factors in the association between social roles and alcohol use among mothers in 16 industrialized countries. Addiction, 106(11), 1925-1932. doi:10.1111/j.13600443.2011.03507.x

Lahelma, E., Arber, S., Kivela, K., \& Roos, E. (2002). Multiple roles and health among British and Finnish women: The influence of socioeconomic circumstances. Social Science and Medicine, 54(5), 727-740.

Little, M., Handley, E., Leuthe, E., \& Chassin, L. (2009). The impact of parenthood on alcohol consumption trajectories: Variations as a function of timing of parenthood, familial alcoholism, and gender.
Development and Psychopathology, 21(2), 661-682. doi:10.1017/S0954579409000352

Maclean, H., Glynn, K., \& Ansara, D. (2004). Multiple roles and women's mental health in Canada. BMC Women's Health, 4(Suppl. 1), S3. doi:10.1186/14726874-4-S1-S3

Martinez, P., Roislien, J., Naidoo, N., \& Clausen, T. (2011). Alcohol abstinence and drinking among African women: Data from the World Health Surveys. BMC Public Health, 11, 160. doi:10.1186/1471-2458$11-160$

McCall, G. J., \& Simmons, J. L. (1996). Identities and Interactions. New York, NY, United States: Free Press.

Neve, R. J., Lemmens, P. H., \& Drop, M. J. (1997). Gender differences in alcohol use and alcohol problems: Mediation by social roles and gender-role attitudes. Substance Use and Misuse, 32(11), 1439-1459.

Peirce, R. S., Frone, M. R., Russell, M., \& Cooper, M. L. (1994). Relationship of financial strain and psychosocial resources to alcohol use and abuse: The mediating role of negative affect and drinking motives. Journal of Health and Social Behavior, 35(4), 291-308.

Prasad, R. (2009). Alcohol use on the rise in India. Lancet, 373(9657), 17-18.

Qian, F., Ogundiran, T., Hou, N., Ndom, P., Gakwaya, A., Jombwe, J., . . Huo, D. (2014). Alcohol consumption and breast cancer risk among women in three subSaharan African countries. PLOS ONE, 9(9), e106908. doi:10.1371/journal.pone.0106908

Rahav, G., Wilsnack, R., Bloomfield, K., Gmel, G., \& Kuntsche, S. (2006). The influence of societal level factors on men's and women's alcohol consumption and alcohol problems. Alcohol and Alcoholism, 41(Suppl. 1), i47-i55. doi:10.1093/alcalc/agl075

Room, R., \& Selin, K. H. (2005). Problems from women's and men's drinking in eight developing countries. In I. S. Obot \& R. Room (Eds.), Alcohol, gender and drinking problems. Perspectives from low and middle income countries (pp. 209-220). Geneva, Switzerland: World Health Organization.

Tumwesigye, N. B., \& Kasirye, R. (2005). Gender and major consequences of alcohol consumption in Uganda. In I. S. Obot \& R. Room (Eds.), Alcohol, gender and drinking problems. Perspectives from low and middle income countries (pp. 189-208). Geneva, Switzerland: World Health Organization.

Wilsnack, R. W., Vogeltanz, N. D., Wilsnack, S. C., Harris, T. R., Ahlstrom, S., Bondy, S., . . . Weiss, S. (2000). Gender differences in alcohol consumption and adverse drinking consequences: Cross-cultural patterns. Addiction, 95(2), 251-265.

Wilsnack, R. W., Wilsnack, S. C., Kristjanson, A. F., Vogeltanz-Holm, N. D., \& Gmel, G. (2009). Gender and alcohol consumption: Patterns from the multinational GENACIS project. Addiction, 104(9), 1487-1500. doi:10.1111/j.1360-0443.2009.02696.x

Wilsnack, R. W., Wilsnack, S. C., \& Obot, I. S. (2005). Why study gender, alcohol and culture? In I.S. Obot \& R. Room (Eds.), Alcohol, gender and drinking problems. Perspectives from low and middle income 
countries (pp. 1-23). Geneva, Switzerland: World Health Organization.

World Bank. (2008a). International comparison program. [Data file]. Retrieved from http://siteresources. worldbank.org/ICPEXT/Resources/ICP_2011.html

World Bank. (2008b). World development indicators and global development finance [Data file]. Retrieved from http://data.worldbank.org/data-catalog/worlddevelopment-indicators

World Bank. (2014). [Data file]. Retrieved from https://datahelpdesk.worldbank.org/knowledgebase/art icles/378834-how-does-the-world-bank-classifycountries

World Health Organisation (2011). Global status report on alcohol and health. Retrieved from http://www. who.int/substance_abuse/publications/global_alcohol_ report/msbgsruprofiles.pdf 